\title{
NUTRIENT DYNAMICS AT THE INTERFACE BETWEEN SURFACE WATER AND GROUNDWATER WITH AQUATIC VEGETATION: AN EXPERIMENTAL APPROACH
}

\author{
LU, X. H. - SONG, M. G. - WANG, P. F. ${ }^{*}$ CHEN, R. \\ School of Earth Science and Engineering, Ministry of Education Key Laboratory of Integrated \\ Regulation and Resource Development on Shallow Lakes, Hohai University \\ Nanjing, Jiangsu, China \\ *Corresponding author \\ e-mail:pfwang2005@hhu.edu.cn \\ (phone :+86-25-83787930/fax: +86-25-83787930) \\ (Received 28 $8^{\text {th }}$ Oct 2016; accepted $28^{\text {th }}$ Feb 2017)
}

\begin{abstract}
To help improve our understanding of the nutrient dynamics at the interface between surface waters and groundwaters, particularly in the context of aquatic plant change, we analyzed total nitrogen (TN) and nitrate $\left(\mathrm{NO}_{3}-\mathrm{N}\right)$ data from experiments. We assessed the effects of aquatic plant, nitrogen $(\mathrm{N})$ and phosphorus (P) loading, water level on $\mathrm{N}$ processing. Laboratory experiments were conducted by percolating vegetated cores containing natural sediment or technical sand with artificial ground water and with either high or low levels of nutrients. 1. The results show that the growth rates of Elodea and Myriophyllum in Laboratory experiments were significantly higher in seepage treatments compared to control treatments, and final plant mass was up to $62 \%$ higher than that for plants where seepage was excluded. In areas with high groundwater discharge, a strong positive correlation was found between groundwater seepage fluxes, growth rates, and final plant mass for Elodea and Myriophyllum.The growth of Elodea and Myriophyllum was also significantly affected by groundwater seepage, but to a lesser degree than Elodea and Myriophyllum. Laboratory experiments generally showed the same trend for both Elodea and Myriophyllum and the positive influence of seeping ground water was apparently related to increased inorganic carbon supply and, to a lesser degree, improved nutrient availability. 2. The nutrient uptake capacity of Myriophyllum verticillatum was higher than that of Elodea nuttallii; Plants control the diffusion flux of nutrients through absorption. under higher concentration of nitrogen source condition, The growth of aquatic plant was better and nutrient uptake capacity of aquatic plant was stronger. 3. Under the conditions of smaller particle size of sediments and greater thickness, hyporheic zone had better prevent and control effect of nitrogen and phosphorus nutrients transport in groundwater; Small particle size of deposit in hyporheic zone can reduce nutrient flux through adsorption and blocking effect, diffusion flux peak had been delied and decreased.
\end{abstract}

Keywords: seepage; lake; Elodea nuttallii; Myriophyllum verticillatum; hyporheic zone

\section{Introduction}

Increased nutrient loading has reduced lake water quality worldwide over the past century (Hester et al., 2013). High concentrations of N may exacerbate eutrophication (Rosenberry et al., 2010) and cause changes in species composition (Ommen et al., 2012), eventually leading to a notable decrease in macrophyte biomass and species richness in shallowlakes (Kidmose et al., 2013).

Influenced by natural factors and human activities, there exist to varying degrees of interaction, water, material and energy exchange between lake water and groundwater, 
and they also played an important role in the terrestrial hydrological cycle. Groundwater - lake interactions become an important control factor in lake ecosystems in many ways. Groundwater lake water balance is an important part of this ground water - lakes recharge and discharge relationship may eventually decide lakes biogeochemical and ecological processes The exchange interface of lake water and groundwater also known as the hyporheic zone is the hub of the communication between lake water and groundwater, and it plays a crucial role in controlling the migration of the nutrient carried by the groundwater during the groundwater seepage process (Frandsen et al., 2012). The interaction between lake and groundwater involves the transportation of water and the result of this transportation also involves the modification of the properties of water like chemical, biological and physical etc. Water transport between groundwater and surface water through hyporpheic zone may have changes the quality of the water of both hydrogeological zones. The water interaction between these two zones also involves the transportation of nutrient. To reduce lake eutrophication, the key is controlling the concentration of nutrients in lakes which can cut off the input of nutrients, and find ways to remove nutrients .Therefore how to control nutrients of groundwater flow seepage into the lake through ground water - lakes interface cause for concern.

Groundwater flow seepage into the lake is different from surface water flow into the lake, because the groundwater flow seepage was poor visibility, and was monitored difficultly and expensive. Therefore, groundwater flow seepage particularly with regard to the contribution of groundwater lakes nutrients has been neglect for a long time and has not been pay attention (Lee et al., 1977). Lake water balance estimates, the amount of groundwater into the lake are more qualitative and less quantitative research, has been affecting the accuracy of the lake water balance and nutrient balance calculations (Linqist et al., 2011). Groundwater seepage occurs near the shores of Lake, with increasing distance from the shore, groundwater flow decreases exponentially (Kang et al., 2005; Boano et al., 2014). This indicates that groundwater flow often occurs in groundwater - Lake Interface (phreatic zone).

Aquatic vegetation is widely distributed in the ground water - lakes interface, $10-15 \mathrm{~cm}$ thick, where groundwater flow before entering the lake. Aquatic vegetation in the lake bottom (the plant can absorb nitrate and nitrate degradation products) . Root capturing fine particles to form a "water barrier" .Groundwater - lake interactions affect between whether to control groundwater by vegetation at the bottom of the lake bed to control seepage nutrients entering the lakes, vegetation root systems at different scales formed "water barrier" has the kind of water and nutrient uptake is the focus of attention in this study.

The importance of groundwater seepage to submerged macrophytes is poorly understood, but some studies suggest that natural variations in seepage can affect the distribution and abundance of these plants (Khadka et al., 2017; Ackerman et al., 2015). However, these studies merely evaluated the abundance of macrophytes in relation to in situ measurements of seepage fluxes. In contrast, Hagerthey and Kerfoot (1998) conducted actual growth experiments on benthic algae to test the effects of groundwater 
seepage and found that seepage stimulated growth and increased the biomass of the algal communities studied. So far, to our knowledge, no growth experiments have been conducted to test seepage effects on submerged macrophytes.

In this research we held experiments in laboratory to examine how seepage of different magnitudes (discharge and recharge) and aquatic vegetation (Elodea and Myriophyllum) affects the nutrient concentration dynamics in lake. Laboratory experiments were carried out by percolating vegetated sediment cores with artificial ground water while manipulating nutrient.

We tested the hypotheses that (i) if and how a lake bottom with underwater vegetation (where plant uptake of nitrate and nitrate reduction may occur) may act as a barrier to seepage and control the loading of nitrate to the lake (ii) groundwater seepage stimulates the growth of submerged macrophytes by increasing the availability of nutrients (iii) how the nutrient concentration in the ground water seepage water influences the nutrient dynamics in lake.

\section{Methods of laboratory experiments}

Growth experiments were conducted in custom-built seepage chambers (Fig. 1a) modified after the study of Lee (1977) to enable growth measurements as well as measurements of seepage fluxes in the same chamber. Seepage chambers were constructed of acrylic cylinders (height $35 \mathrm{~cm}$, inside diameter $15 \mathrm{~cm}$ ) and had either open bottoms covered with wire netting $(0.7 \mathrm{~mm}$ mesh size $)$ allowing seepage to freely flow through (seepage chambers) or closed bottoms preventing seepage flow (control chambers).

In order to investigate the different types of aquatic vegation influence nitrogen and phosphorus nutrient transportation, Elodea and Myriophyllum were used as a contrast in the experiment. Elodea nuttallii is a species of waterweed known by the common name western waterweed or Nuttall's waterweed. This is a perennial aquatic plant which is native to North America where it grows submersed in lakes, rivers, and other shallow water bodies. Myriophyllum verticillatum, the whorl-leaf watermilfoil or whorled water-milfoil, is native to much of the North America, North Africa, and Eurasia (Wikipedia). The submersed leave, which looks feathery and contain about 5 to 14 leaflet pairs per leaf. The whorls along the stem contain about 4 to 5 leaves, which are spaced about $1 \mathrm{~cm}$ apart. From June till September whorled water milfoil produces flowers and fruits above or at the water's surface on erect spikes along the emergent leaves.

\section{Experimental setup}

Two tubes were used in experiments. There were 10 Elodea nuttallii in tube 1, which the lengths were $10 \sim 15 \mathrm{~cm}$. There were 10 Myriophyllum verticillatum in tube 2 , which the lengths were $10-20 \mathrm{~cm}$. The total aquatic vegetation were seedling in experiment. The coarse sand which particle size range were $0.5-1 \mathrm{~mm}$ used as the 
sediment in two tubes. The thickness of sediment was $5 \mathrm{~cm}$, experiment parameters were seen in the table. The concentration of TN and TP of artificial lake water were measured in two tubes through experiments, and removal rate of nitrogen and phosphorus nutrient were calculated separately. The transportation law of different aquatic vegetation in interface of surface water and ground water were investigated through the concentration of nitrogen and phosphorus nutrient. In artificial groundwater, nitrogen nutrient type was nitrate, the concentration of TN was $50 \mathrm{mg} / \mathrm{L}$, phosphorus nutrient type was phosphate, the concentration of TP was $2.5 \mathrm{mg} / \mathrm{L}$.

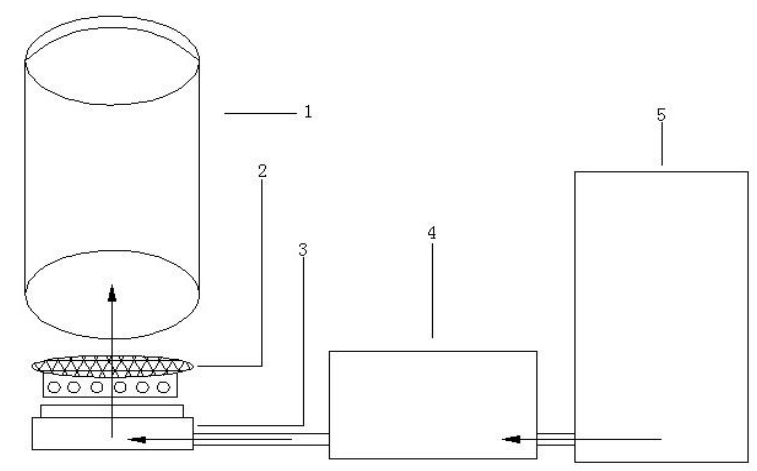

Figure 1. Flow-through chambers used in the laboratory experiments

1. Top chamber; 2. Perspex filter with mesh; 3. Bottom chamber; 4. Peristaltic pump 5.

Gas-tight bag with artificial seepage water

Environment: Indoors, temperature $20^{\circ} \mathrm{C}$, evaporation ( $14 \mathrm{~d}$ evaporation $23 \mathrm{~mm}$ ). Design: nutrient nitrogen and phosphorus at fixed concentration (in the form of $\mathrm{KNO}_{3}$ and $\mathrm{Na}_{2} \mathrm{HPO}_{4}$ ), artificial groundwater flow through the different thickness of sediments and different aquatic vegetation and into artificial lake. Total phosphorus and total nitrogen were determined in artificial lake water every $24 \mathrm{~h}$.

Sediment and plant processing: Sediments were coarse sand which the particle size were $0.5-1 \mathrm{~mm}$, aquatic vegetation was Myriophyllum verticillatum. 8 Myriophyllum verticillatums were planted in seepage and control chamber immediately which the length was $13 \mathrm{~cm}$. All leaves were counted and marked with a permanent marker. Upon harvest, Plants were gently washed out of the sediment. Myriophyllum alterniflorum was harvested after 31 days, and final root and shoot fresh mass were measured before being frozen at $-20{ }^{\circ} \mathrm{C}$. Relative growth rates (RGRs) based on fresh mass were calculated under the assumption of exponential growth using the equation:

$R G R\left(\mathrm{~d}^{-1}\right)=\left(\ln \left(\mathrm{w}_{1}\right)-\ln \left(\mathrm{w}_{0}\right)\right) / \mathrm{t}(\mathrm{d})$ where $\mathrm{w}_{0}$ and $\mathrm{w}_{1}$ are the fresh mass at the start and end of the experiment and $t(d)$ is the incubation time in days.

Elodea nuttallii was harvested after 14 days using the same approach as for Myriophyllum verticillatum. Final fresh mass of roots and shoots were measured, and the number of old and new leaves was noted before being frozen at $-20^{\circ} \mathrm{C}$. The relative leaf production (LP) was calculated as follows: $L P\left(\mathrm{~d}^{-1}\right)=\left(\right.$ leaves $_{1} /$ leaf $\left._{0}\right) / \mathrm{t}(\mathrm{d})$ 
where leaves 1 is the number of new unmarked leaves at the end of the experiment, leaf $_{0}$ is the number of leaves at the beginning (leaves were included when longer than $1 \mathrm{~mm}$ ) and $\mathrm{t}$ is the incubation time (days).

Each treatment was percolated with artificial ground water (two-compartment seepage chambers, $n=4)$ and compared with control chambers $(n=4)$ with no percolation. The bottom compartment of the seepage chambers had a solid acrylic filter, covered with wire netting, to separate top and bottom compartments and acted as diffuser to ensure homogeneous percolation of artificial ground water over the entire area of the column (Fig. 2).
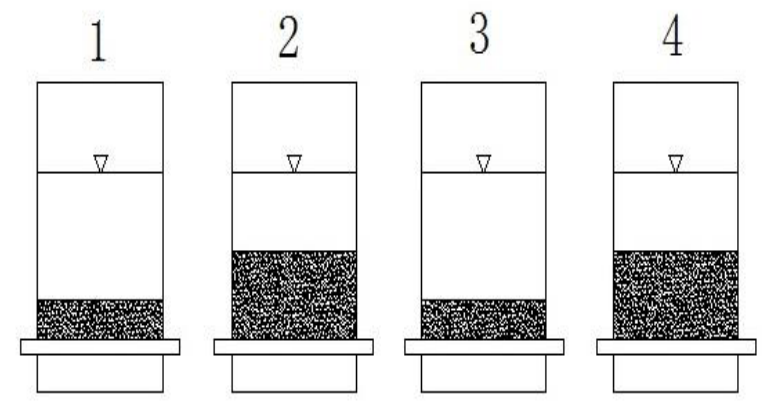

Figure 2. The sediments in test tube

Artificial ground water was percolated through the seepage chambers using a peristaltic pump through Tygon tubing connected to the bottom compartment. The acrylic top compartment (height $35 \mathrm{~cm}$; inner diameter $15 \mathrm{~cm}$ ) was fitted to the bottom compartment and filled with sandy sediment. The growth chambers were filled with either technical sand. The initial concentrations of total nitrogen, total phosphorus and total organic matter in the two substratum types are listed in Table 1. The chambers were placed in two 300-L tanks with artificial lake water mimicking the water of Xuanwu Lake (Table 1) and rotated weekly to minimise boundary effects caused by differences in circulation and light availability.

\section{Artificial ground water and surface water}

Artificial ground water (Table 1) was made from deionised water and to simulate natural ground water, the water was made anoxic by bubbling with $\mathrm{N}_{2}$, and the alkalinity was raised by adding equal amounts of $\mathrm{KHCO}_{3}$ and $\mathrm{NaHCO}_{3}$. Subsequently, hydrochloric acid was added to lower the $\mathrm{pH}$ (Table 1). Nutrients were added as $\mathrm{KNO}_{3}$, $\mathrm{NaH}_{2} \mathrm{PO}_{4}, \mathrm{CaCl}_{2}$ and $\mathrm{MgSO}_{4}$ (Smart \& Barko, 1985), and S, B, Cu, Fe, Mn, Mo and $\mathrm{Zn}$ were added as commercial micronutrients.

Then, the artificial ground water was siphoned into gas-impermeable bags that were connected to the peristaltic pump and percolated through seepage chambers at rates. Artificial lake water was made in a similar way (Table 1). The temperature was $20^{\circ} \mathrm{C}$, 
and all experiments were kept in a 12-h light/dark cycle to keep the water clear from planktonic algae.

Table 1. Nutrient concentration in the sediment, the artificial seepage water and the surface water used in the laboratory experiments

\begin{tabular}{ll}
\hline & Technical sand \\
\hline \multicolumn{1}{c}{ I Sediment type } & \\
TN in sediment(\% DW) & $0.001 \pm 0.0005$ \\
TP in sediment(\% DW) & $0.002 \pm 0.001$ \\
Organic matter(\% DW) & $0.001 \pm 0.0001$ \\
$\quad$ II Artificial seepage water & \\
& \\
NO3- in seepage (m mol) & 50 \\
PO4 3- in seepage (m mol) & 2.5 \\
$\quad$ III Artificial surface water & \\
& \\
TN (mg L-1) & 0.001 \\
TP (mg L-1) & 0.001 \\
\hline
\end{tabular}

\section{Results and discussion}

\section{Effect of aquatic vegetation on nutrient transportation}

Two parallel experiments were designed in this study, the purpose of the first experiment was to measure different nutrient absorption ability between different plant species(Elodea nuttallii and Myriophyllum verticillatum). The second experiment was simulating the different influences on nutrient transportation between the different particle size of sediment, which the aquatic plant was Myriophyllum verticillatum and the particle size of sediment were coarse $(0.5-1 \mathrm{~mm})$ and pebbles $(1-5 \mathrm{~cm})$ in the experiment.

The experiment last 10 days, the artificial lake water was extracted every $24 \mathrm{~h}$ to measure the concentration of TN and TP. The results of the experiment show that the concentration of TN and TP in two tubes along with the time change of curve were contrasted, and the nutrient transportation rules of different aquatic plants in hyporheic zone were studied.

From Fig. 3, the concentration of $\mathrm{TN}$ in tube was a growing trend over time and become flat in the late experiment. In the period, nitrate in artificial ground water will dual influenced by sediment adsorption and plant roots. Through comparing the two curves of total nitrogen in the test tube, the concentration of TN in Myriophyllum verticillatum tube was lower than in Elodea nuttallii tube. Therefore, it showed that the nitrate adsorption ability of Myriophyllum verticillatum was better than Elodea nuttallii under the same condition. 


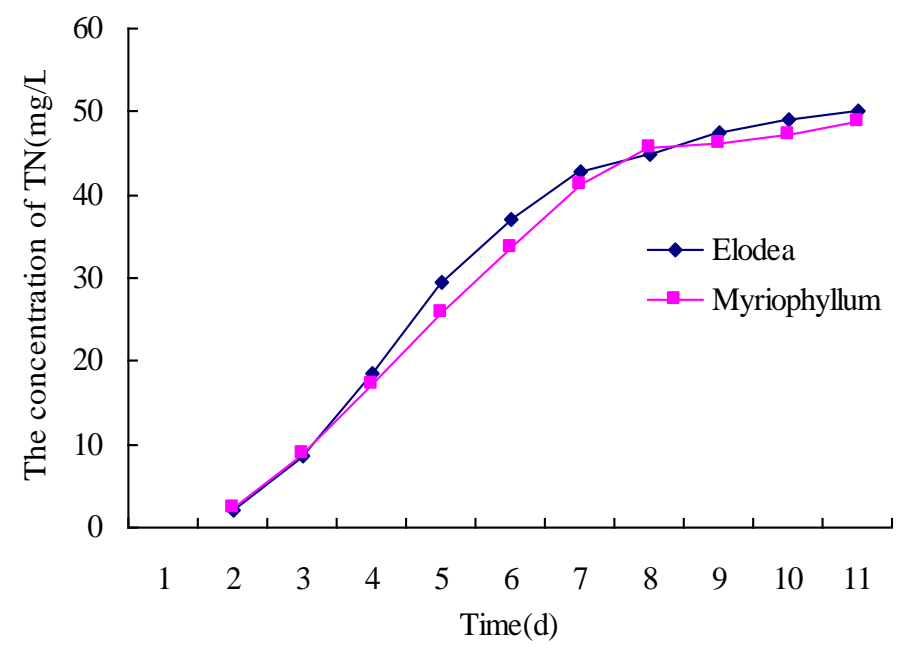

Figure 3. The concentration curve of TN in tube

From Fig. 4, after the slow growth process of TP concentration in two tubes, In the middle of the experiment TP concentration was growing rapidly, and in the late experiment TP concentration was leveled off again. From the curve of TP concentration, phosphorus nutrient in groundwater will induce block impact on total phosphorus concentration in the lake through hyporheic zone. For the phosphorus nutrient in groundwater, adsorption of sediment and aquatic plant root absorption effect was very obvious.

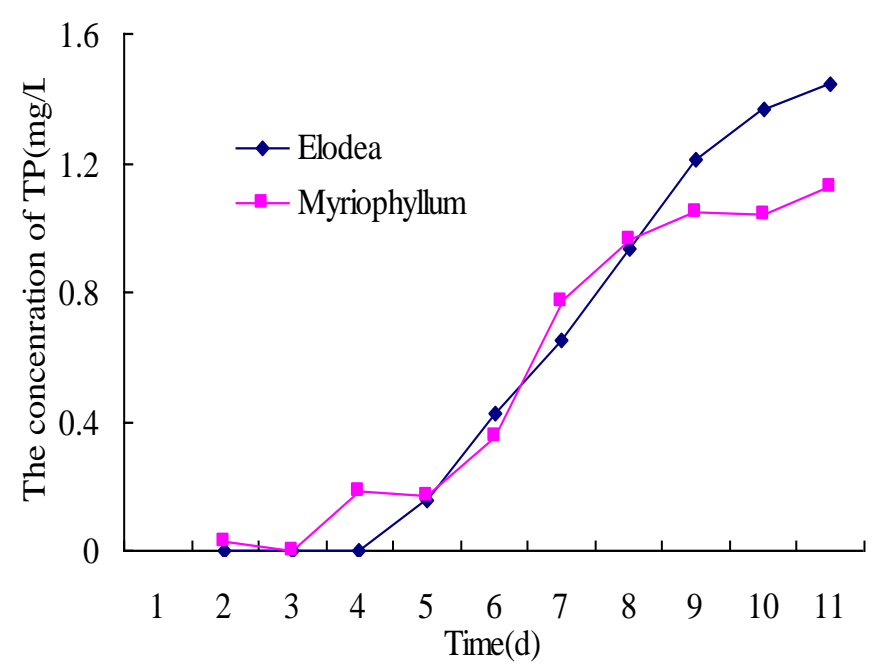

Figure 4. The concentration curve of TP in tube

Nutrient removal rate of nitrogen and phosphorus in hyporheic zone was shown in the figure. In the experiment cycle, the removal amount of TN (nitrogen) were 15.06 $\mathrm{mg}, 17.54 \mathrm{mg}$ in hyporheic zone of tube 1 and tube 2 , and removal rates were $16.2 \%$ 
and $17.9 \%$ respectively; removal amount of $\mathrm{TP}$ (phosphorus) were $2.56 \mathrm{mg}$ and 3.05 $\mathrm{mg}$ respectively, and the removal rates were $51.7 \%$ and $62.1 \%$ respectively. In Myriophyllum verticillatum as the submerged plant of hyporheic zone the nitrogen and phosphorus nutrient removal rate was $10.6 \%$ and $20.2 \%$ higher than in Elodea nuttallii of hyporheic zone respectively.

Fig. 5 was Nitrogen and Phosphorus nutrient concentrations in lake water change curve. The relationship between input flux of TN and TP in each tube and diffusion flux of sediment and water interface can be found, in such scale, nutrient absorption capacity of Myriophyllum verticillatum for nitrogen and phosphorus was slightly higher than that of Elodea nuttallii.
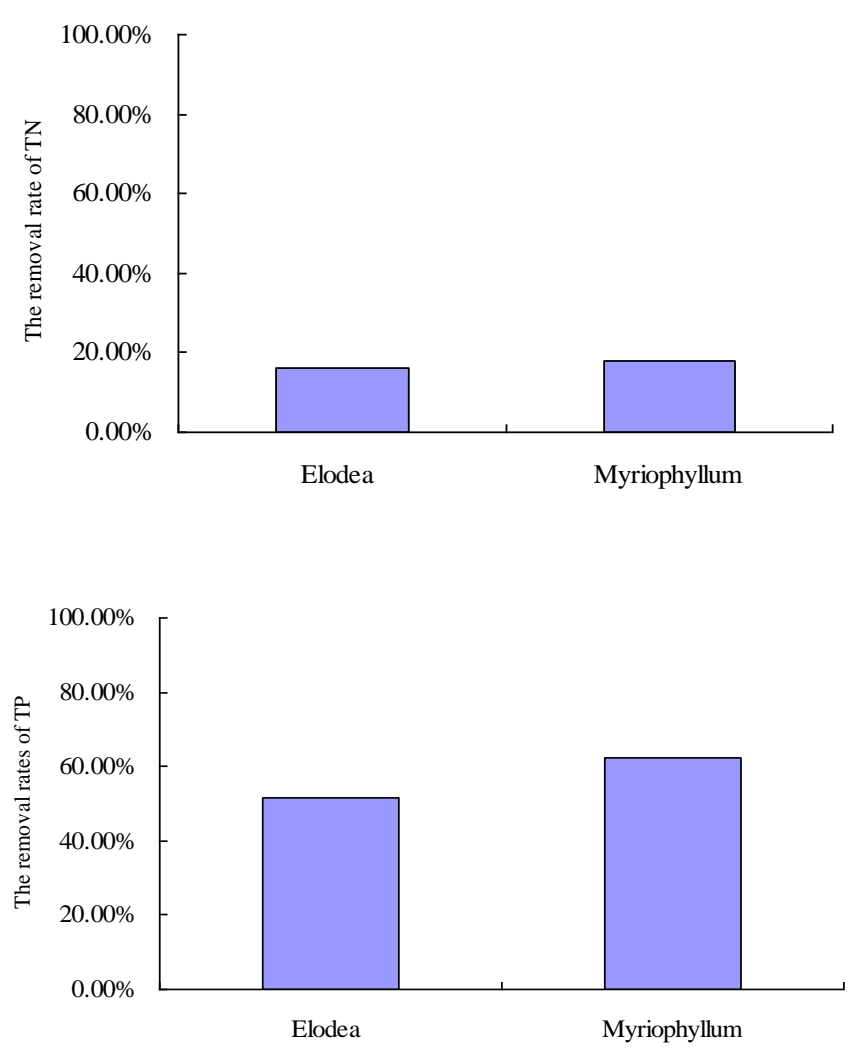

Figure 5. The removal rates of TN and TP using different aquatic vegetation

\section{Effects of groundwater seepage on in situ growth}

The same as the previous experiments, this experiment analyzed the rule of nutrient transportation in groundwater seepage through the concentration of TN and TP in each tube and the adsorption rates. In addition, The experiment subdivided the nutrient removal ability of various components in hyporheic zone through statistical sediment adsorption of soluble nitrogen and phosphorus nutrient, and leaf production of aquatic vegetation (LP) and relative growth rate (RGR) in each tube were calculated to study 
the aquatic vegetation growth under the different thickness of sediments and different concentration of nutrient conditions (Fig. 6).
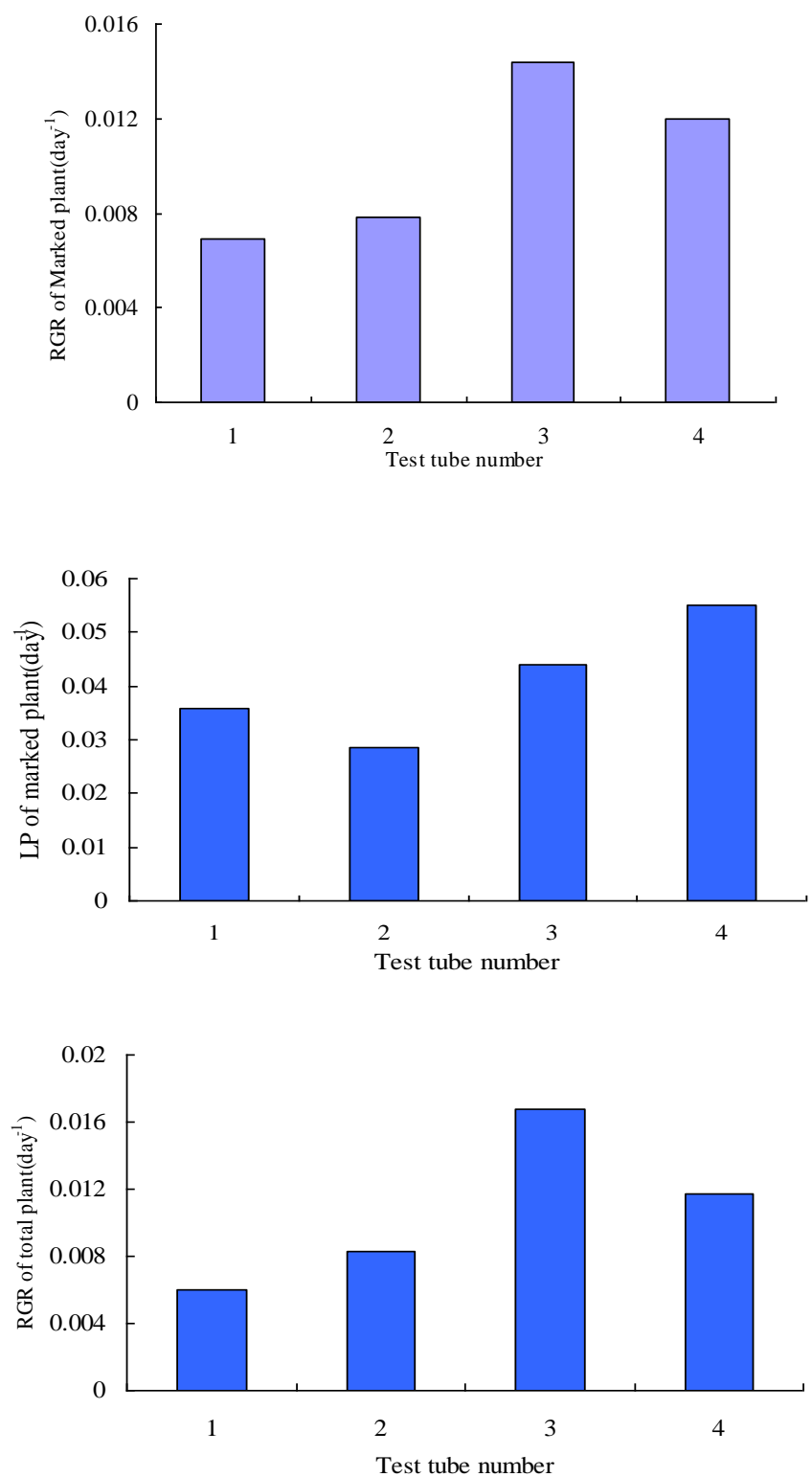

Figure 6. The relative growth rate of plant in the tube

\section{Conclusion}

In the early period of experiment, nutrient concentration in artificial lake was increased more slowly, especially in TP. Nutrient concentration was almost undetectable in the early period of experiment. It showed that groundwater flow through hyporheic zone and influenced the nutrient concentration in surface water; the nutrient concentration in surface water was controlled by the sediment and root 
adsorption. The controlled effect had the relationship with the sediment adsorption capacity; specific conclusions need further study;

Due to different aquatic plants for nutrient absorption ability was different, therefore it will influence nutrient removal ability of groundwater seepage in hyporheic zone. nitrogen and phosphorus nutrient absorption ability of Myriophyllum verticillatum was greater than of Elodea nuttallii, from the relationship be between the input flux of TN and TP in each tube and diffusion flux of sediment-water interface, we found that the controlled effect of Myriophyllum verticillatum in hyporheic zone was not equal to Elodea nuttallii, but latter the controlled effect of Myriophyllum verticillatum in hyporheic zone was beyond Elodea nuttallii. And The later in the experiment, the gap was more obvious, because of different growth ability of aquatic plants. In the end of the experiment, quality, length, leaf area and root length of Myriophyllum verticillatum were better than Elodea nuttallii, which growth and development status of Myriophyllum verticillatum was better than Elodea nuttallii during the process of experiment, therefore it was useful for nutrient absorption ability;

In a certain scale, the hyporheic zone in the same conditions had different removal ability of nitrogen and phosphorus respectively, and the gap of removal ability of nitrogen and phosphorus was very obvious. The removal ability of nitrogen in two groups of experiment were $16.2 \%$ and $17.9 \%$, while the removal ability of phosphorus were $51.7 \%$ and $62.1 \%$.Because of the different concentration of nitrogen and phosphorus in artificial groundwater, Thus it can be seen sediment adsorption and plant root absorption was considerable for the removal effect of phosphorus.

Acknowledgments. This study was financed by the National Science Foundation for Distinguished Young Scholars of China (Grant No.41202172), Open Research Fund Program of Resource Development on Shallow Lakes and Center for Agricultural Resources Research, Institute of Genetics and Developmental Biology, The Fundamental Research Funds for the Central Universities.

\section{REFERENCES}

[1] Ackerman, J. R., Peterson, E. W. (2015): Quantifying nutrient removal from groundwater seepage out of constructed wetlands receiving treated wastewater effluent. - Environmental Earth Sciences 74:1-13.

[2] Boano, F., Harvey, J. W., Marion, A., Packman, A. I., Revelli, R., Ridolfi, L., Wörman, A. (2014): Hyporheic flow and transport processes: Mechanisms, models, and biogeochemical implications. - Reviews of geophysics 1-77.

[3] Frandsen, M., Nilsson, B., Engesgaard, P., Pedersen, O. (2012): Groundwater seepage stimulates the growth of aquatic macrophytes. - Freshwater Biol. 57:907-921

[4] Hester, E. T., Young, K. I., Widdowson, M. A. (2013): Mixing of surface and groundwater induced by riverbed dunes: Implications for hyporheic zone definitions and pollutant reactions. - Water Resour. Res. (49):5221-5237.

[5] Kang, W.J., Kolasa, K.V., Rials, M.W. (2005): Groundwater inflow and associated 
transport of phosphorus to a hypereutrophic lake. - Environ. Geol. 47: 65-575.

[6] Khadka, M., Martin, J. B., Kurz, M. J. (2017): Synoptic estimates of diffuse groundwater seepage to a spring-fed karst river at high spatial resolution using an automated radon measurement technique. - Journal of Hydrology 544:86-96.

[7] Kidmose, J., Nilsson, B., Engesgaard, P.,Frandsen, M., Karan, S., Landkildehus, F., S dergaard, M., Jeppesen, E.(2013): Focused groundwater discharge ofphosphorus to a eutrophic seepage lake: Implications for lake ecological stateand restoration. Hydrogeol. J.21:1787-1802.

[8] Lee, D.R. (1977): A device for measuring seepage flux in lakes and estuaries. - Limnol. Oceanogr. 22: 140-147.

[9] Linqist, B. A., Ruark, M. D., Hill, J. E. (2011): Soil order and management practices control soil phosphorus fractions in managed wetland ecosystems. - Nutrient Cycling in Agroecosystems 90(1): 51-62.

[10] Ommen, D.A.O., Kidmose, J., Karan, S., Flindt, M.R., Engesgaard, P., Nilsson, B., Andersen, F. (2012): Importance of groundwater and macrophytes for the nutrient balance at oligotrophic Lake Hampen, Denmark. - Ecohydrology 5: 286-296.

[11] Rosenberry, D.O., Toran, L., Nyquist, J.E. (2010): Effect of surficial disturbance on exchange between groundwater and surface water in nearshore margins. - Water Resour. Res. (46): 131-142. 